\title{
Is CAMHS suitable for a GP training placement?
}

When I first found out that my psychiatry rotation, as part of my general practice training, was in The Child and Adolescent Mental Health Service (CAMHS) my feelings were rather mixed. Was this an opportunity to encounter conditions and problems that GPs commonly face and find difficult to deal with, over and above the traditional psychiatric experiences of GP trainees? Or was this an overspecialised placement that would give me only limited exposure to the common dayto-day psychiatric problems, yet expose me to conditions that are not the remit of a GP? My only experience of CAMHS so far had been as a referrer while completing a placement in paediatrics, and my knowledge stretched no further than the NICE guidelines on ADHD, and the use of alarms and pads in nocturnal enuresis. After only a matter of weeks at CAMHS however, I realised the huge relevance of child and adolescent mental health to GPs.

Every child who comes through the door has not just got an illness that needs to be treated. There are psychological and social factors (which are the mainstay of GP consultations) to explore and understand. Indeed, these often dominate the session. Liaison with the child's school is a valuable source of further information, and can reveal the consequences of the underlying illness. Terms such as 'SENCO' (special educational needs coordinator) and 'Statementing' (a process which allows children to receive additional support at school), often become pivotal to the understanding of how children are affected by their condition and circumstances. Social services' involvement is commonplace, and the forest of names surrounding some of the family trees is astounding. In some cases it is clear that the parents accompanying the child have significant psychological or social problems themselves (whether that be cause or effect), and it is important therefore to consider the family unit as a whole.

I can imagine children, such as the ones I see daily, being taken to their GP by frustrated and exhausted parents asking for help, and in 10 minutes a differential diagnosis needs to be made, the concerns and expectations of the parent and child considered, and the plan made and communicated. That still leaves the referral, potential communication with the child's school and social services, safety-netting, and follow-up. It may even be worthwhile seeing one or both parents on their own to deal with their own issues, such as depression or anxiety. Nearly every case I have seen would have first been filtered through primary care, and with this in mind I took the opportunity to look into the role of child and adolescent mental health in the Royal College of General Practice (RCGP) Curriculum, to see whether it is adequately represented.

The RCGP states that there are currently 1 million children in the UK with a mental health disorder, and 400000 children and young people in need. ${ }^{1}$ The Office of
National Statistics (2005) cites a similar figure, with $10 \%$ of children between the age of 5 and 15 years being said to have a clinically significant mental disorder. ${ }^{2}$ Mental health specialists never encounter the majority of these children, indeed, some never present to medical services of any kind. However, the GP will come across a considerable number of these young people, and will have to manage a complex array of psychological, behavioural, and social issues. In adults with mental health problems, $80 \%$ of all $\mathrm{NHS}$ contacts are within primary care, and a similar figure is likely in children and adolescents. $^{3}$

The RCGP does not consider child and adolescent mental health as a singular topic. Rather it is considered within three RCGP Curriculum Statements (Box 1) due to the fact that it rarely occurs in isolation, and often requires a multidisciplinary approach. This could encompass mental health specialists, teachers, GPs, SENCOs, social workers, counsellors,

\section{Box 1. RCGP Curriculum Statements with particular relevance to child and adolescent mental health.}

Curriculum Statement 8: Care of Children and Young Adults ${ }^{1}$

Knowledge Base:

- Mental health problems such as attention-deficit hyperactivity disorder, depression, eating disorders, substance misuse and self-harm, autistic spectrum disorder, and related conditions.

- Psychological problems: enuresis, encopresis, bullying, school refusal, behaviour problems including tantrums.

- Recognise inappropriate eating habits, such as the development of anorexia nervosa or bulimia, and be able to make appropriate referrals if specialist help is required.

Curriculum Statement 13: Care of People with Mental Health Problems. ${ }^{3}$

Describe the varied ways that young people developing a first episode of psychosis present.

Describe early indicators of difficulty in the psychological wellbeing of children and young people.

- Respond quickly to concerns raised by parents, family members, early-years workers, teachers, and others who are in close contact with the child or young person.

Curriculum Statement 14: Care of People with Learning Disabilities. ${ }^{4}$

- Understand responsibilities for supporting children in difficulty and know how to access support and advice from specialist Child and Adolescent Mental Health Services (CAMHS) and CAMH workers in primary care. 
health visitors, psychologists, and play or music therapists.

Child and adolescent mental health is therefore a significant public health issue, and has been considered as such by the RCGP. However, due to the scarcity of CAMHS clinics (there are five in the whole of East Kent), it is an area to which GP trainees are rarely exposed. I would strongly advise all trainees to arrange 1 or 2 days at a local CAMHS clinic, to experience the set-up of local services, find out what therapeutic interventions are used, and see some of the common conditions (such as ADHD, school refusal, and self-harm). I for one have greatly valued my experience so far, and feel that I would be able to deal with many of the problems that GPs encounter given adequate time. I also feel that my experience has not detracted from areas of the curriculum pertaining to adult mental health, as there is a concurrent well-organised teaching programme and on-call commitments allow exposure to adult services.

CAMHS at the present time is a relatively overstretched service, so the ability to filter referrals and provide follow-up for children and young adults with mental health disorders (for example, stable ADHD cases) would be an extremely valuable service to offer in general practice. At present there are very few GPs who specialise in these kinds of problem, and providing a service to deal with common child and adolescent mental health issues is something I would seriously consider when I have completed my training.

\section{Allan James Smith}

\section{REFERENCES}

1. Royal College of General Practitioners. Curriculum Statement 8: Care of children and young people. http:// www.rcgp-curriculum.org.uk/PDF/curr_8_Care_of_ Children_and_Young_People.pdf (accessed 14 Apr 2009).

2. Green H, McGinnity A, Meltzer, H, et al. Mental health of children and young people in Britain 2004. London: Palgrave MacMillan, 2005.

3. Royal College of General Practitioners. Curriculum Statement 13: Care of people with mental health problems. http://www.rcgp-curriculum.org.uk/PDF/ curr_13 Mental_Health_Problems_vl_2 feb09.pdf (accessed 14 Apr 2009).)

4. Royal College of General Practitioners. Curriculum Statement 14: Care of people with learning disabilities. http://www.rcgp-curriculum.org.uk/PDF/ cur_14_ Learning_disabilities.pdf (accessed 14 Apr 2009).

DOI: 10.3399/bjgp09X420743

\section{Mike Fitzpaurick}

\section{Treating autism appropriately}

The Treating Autism campaign decided at its recent 'second international biomedical conference' in Bournemouth to provide parents with an open letter to their GPs together with a complimentary copy of a book promoting 'unorthodox biomedical' interventions for their children. Recommended treatments include exclusion diets, vitamins and supplements, heavy metal chelation therapy and medication with antibiotics, antifungals, and other drugs. ${ }^{2}$ Given that Treating Autism offers the prospect of 'lifechanging improvements', indeed of children 'losing their diagnosis', and recovering from autism, we can expect to see more parents in our surgeries demanding these treatments in the near future. It may therefore be useful for GPs to know something about this campaign.

The guest of honour at the second Bournemouth conference (as at the first in 2007) was Andrew Wakefield, the leading promoter of the claim for a link between the MMR vaccine and autism, now based in a private clinic in Texas. The conference featured several prominent figures from the Defeat Autism Now! campaign in the US, which links parents to 'DAN! practitioners' (certified by attending a course lasting a few hours) and to a multimillion dollar network of laboratories and suppliers of biomedical products (which also sponsored the Bournemouth event).

I would like to be able to report in more detail on the Bournemouth conference, but after I asked a few questions at the first conference, I was banned from the second. The conference platform included not a single paediatrician or autism specialist or GP, or any medical doctor practising in the NHS.

One of the few platform speakers based in the UK was 'Dr' T Michael Culp, who is actually a naturopath rather than a medical doctor. He runs a Harley Street clinic offering testing and treatment for adults with chronic fatigue and similar conditions. Another was Natasha Cubala-Kucharska, a DAN! practitioner qualified in both conventional and alternative medicine in Poland. She is attached to a private clinic in Hertfordshire that has long specialised in 'allergy and environmental illness'. It provides chelation for a range of conditions and sells separate measles, mumps, and rubella vaccines.
The common features of the treatments recommended are the absence of any coherent scientific rationale and lack of evidence of efficacy or safety. Though most are probably harmless as well as useless, this is not the case for some of the more intensive treatments, such as chelation, from which one British child has already died in the US. ${ }^{3}$ The book being donated to GPs by Treating Autism recommends treating 'autistic enterocolitis' - a condition not recognised by any reputable medical authority - with steroids, immunosuppressants and antiTNF drugs. ${ }^{2}$ In the US, children with autism attending DAN! practitioners endure not only repeated blood tests, but also multiple gastroscopies, colonoscopies, and lumbar punctures. ${ }^{4}$

How should GPs respond to parents bearing the Treating Autism appeal? One of the lessons of the MMR debacle is of the importance of upholding serious science against pseudoscience, and of professional practice based on evidence against that based on anecdote, dogma, and speculation. We should emphasise to parents that for us, as for them, the interests of the child must come first and that this means not subjecting children to unvalidated tests and untested treatments. We could also encourage parents to be more critical of the claims made for biomedical interventions and more questioning of the qualifications, experience, and expertise of those offering them.

It is also important that the medical mainstream does not give legitimacy to pseudoscience. The fact that the Bournemouth 'quack-fest' was 'awarded ten credits' for postgraduate education by the Royal College of Physicians was proudly trumpeted in the programme and repeated in the open letter to GPs. This sort of endorsement gives junk science an aura of respectability and serves only to confuse parents.

\section{REFERENCES}

1. Treating autism. http://www.treatingautism.co.uk (accessed 9 Apr 2009).

2. Jepson B, Johnson J. Changing the course of autism: a scientific approach for parents and physicians. Colorado, US: Sentient, 2007.

3. Fitzpatrick M. Defeating autism: a damaging delusion. New York: Routledge, 2009

4. Fitzpatrick M.MMR-autism scare: the truth is out at last. Spiked Online, 23 February, 2009 http://www.spiked-online.com/index.php?/site/ article/6283/ (accessed 9 Apr 2009).

DOI: 10.3399/bjgp09X420770 